\title{
RELATION OF PLANT SIZE TO POWER COST
}

\author{
BY \\ P. M. LINCOLN
}




\section{RELATION OF PLANT SIZE TO POWER COST}

BY P. M. LINCOLN

\section{Abstract of Paper}

The author gives three principal reasons why a central station plant can take care of a given service more economically than a small plant. First, because the first cost per kilowatt of the large units is lower than the corresponding cost of the small units, thereby reducing the first cost and the annual fixed charges. Second, because the operation of a large plant is proportionally less than that of a small plant, and because the large plant can afford to make use of labor saving and other devices which would be out of the question in a small plant. Third, because of the existence of a diversity factor whereby a combined load can be operated with a smaller total capacity than would be required if each part of the combined load were operated separately. The author concludes that the only reasons why central stations should not supply all the electrical service within their territory are that the rates offered may be out of proportion to the cost of the service, or that the customer may have some motive other than the cost of the supply for not using central station service. 
Copyright 1913 by A. I. E. E.

(Subject to final revision for the Transactions.)

\title{
RELATION OF PLANT SIZE TO POWER COST
}

\author{
BY P. M. LINCOLN
}

That a large plant can supply a given power service as a part of a general power supply business more economically than a plant of only sufficient size for that given service, is so manifest that most engineers are ready to admit it without argument. However, every isolated plant that is installed where central station service is available is, to a certain extent, evidence that there is somebody not yet convinced of this general truth; consequently a discussion showing why this general statement is true may not be out of place.

There are three distinct reasons why a large plant can take care of a given service more economically than a small one. These reasons are:

1. Because the first cost per kilowatt of the large units entering into the construction of a large plant is lower than the small units entering into the construction of a small plant, thereby reducing the first cost of the apparatus necessary for the given service and, therefore, reducing the annual fixed charges thereon.

2 . Because a large plant inherently can be operated more economically than a small one, and because, further, the large plant can afford to introduce economies which would be out of the question in a small one.

3 . Because of the existence of diversity factor, whereby one kilowatt of capacity in a central station will serve a combined load that would take considerable more than one kilowatt if each part of that combined load were to be served separately.

Further discussions of these three reasons will be taken up in the order named above. 


\section{Relation of Size and First Cost}

A large plant will cost less per kilowatt than a small one. This is simply a specific statement of a general law. The larger the amount involved, the cheaper each unit becomes, no matter what the commodity may be: Kilowatts come cheaper when purchased a thousand in one machine than when bought singly; just as cigars come cheaper by the box, or freight rates are lower by the car.load.

Although this law is usually recognized qualitatively, few engineers have an adequate conception of how much it means quantitatively. To give some idea of the extent to which this reduction in cost occurs, a number of curves are given herein showing approximately how much the size affects the cost per kilowatt of some of the types of apparatus that enter into the

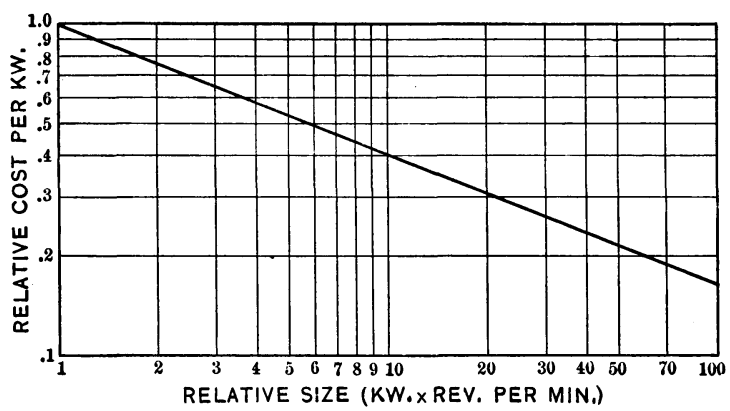

FIG. 1

make-up of a power station. In giving these data, logarithmic cross-section paper is used for two reasons; first, because the range of the data covered in a given curve may be thereby increased, and second, because the law connecting size and cost per kilowatt usually takes an exponential form, thereby enabling us to represent the relation by a straight line on this kind of paper.

Fig. 1 gives data of this nature upon electric generating apparatus. In apparatus of this kind, a variation in size is almost invariably accompanied by a simultaneous variation in speed, and both speed and size have an important influence upon the cost per kilowatt. It is quite possible, however, to take cognizance of the speed variation as well as the output variation and to derive a law that couples the cost per kilowatt with both output and speed. The data given in Fig. 1 are the result of 
the inspection of a considerable number of electric generator costs. This curve shows the relative variation of cost per kilowatt as it depends upon size and speed of generator units. An inspection of the curve will show, for instance, that if the speed

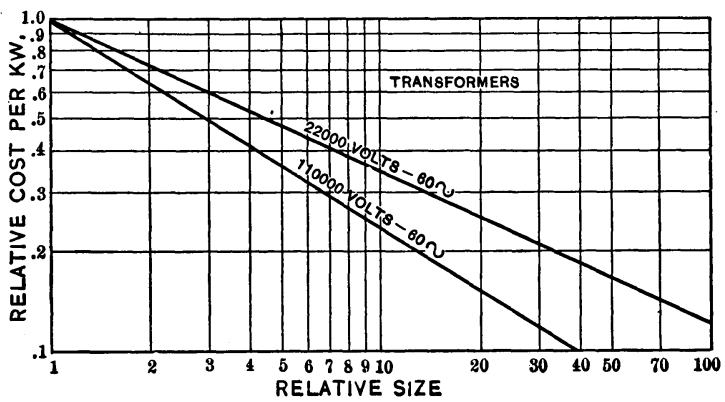

FIG. 2

remains constant the cost per kilowatt will decrease by approximately 65 per cent for an increase of ten fold in the size of the unit.

In Fig. 2 similar data are given for some typical lines of transformers.

In Fig. 3 data are given upon the relative costs of different sizes of boilers.

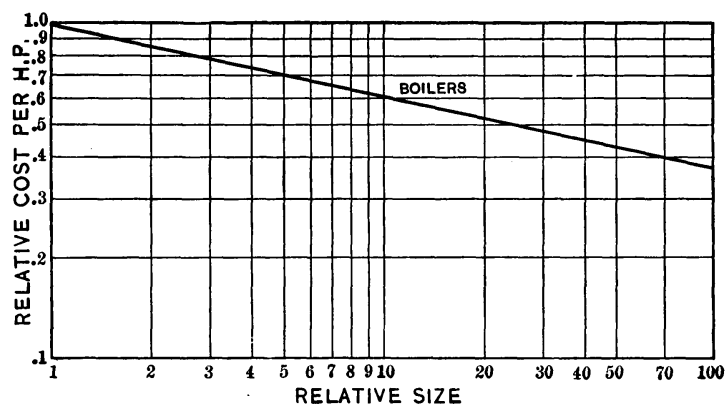

Fig. 3

In using any of these curves it must be borne in mind that a curve is simply a method of stating a general law and that no such general law can take cognizance of an unusual condition. For instance, if we tried to extend the curve for 110,000-volt transformers so as to obtain the cost of a one-kw. transformer, the result would be absurd. When an engineer has designed the 
smallest possible transformer suitable for use on 110,000 volts he will necessarily have a transformer of a capacity very much in excess of one kilowatt. In other words, it is impossible to design a transformer of so high a voltage and so low an output. As a consequence, therefore, the use of these curves to obtain relative costs for such conditions would lead to a result which is sadly in error. Common sense must be used in the application of these data.

Comparing a large central station suitable for delivering power for every purpose with the size of a plant that an individual customer of that central station would have to install, if he supplied his own wants, we will find, of course, that the central station plant will be very much larger, anywhere from ten to a thousand fold, possibly even more. However, in comparing complete plants with such a difference in size, we will find that we do not realize the whole of the difference in cost that would be indicated by comparing difference in the cost of the individual parts. The reason for this is that the large plant is inherently more elaborate than the small one. A large plant will naturally be equipped with such items as mechanical stokers, coal and ash handling machinery, coal bunkers and storage yards, superheaters, economizers, condensers with all their auxiliaries, double sets of bus bars, distant control electrically operated switches, heat insulating lagging on all boilers and steam pipes, feed water heaters, water softening plant, etc., some or all of which items may be omitted from the small plant. Although such items cause an increase in the first cost of the large plant, they still do not run its cost up to be as much per kilowatt as the small plant not equipped with these refinements. In the large plant the first cost of these items is more than offset by the operating cost which their use will save and that fact accounts for their use. On the other hand, as the size of the plant is reduced, the point is approached where these cost-saving items may one by one be eliminated, owing to the fact that their presence will lead to a greater resultant cost of power than their absence. It is only where power is produced in relatively large quantities that these various cost-saving devices will pay. This matter will be treated further under the next heading in this paper.

Another saving which would be effected by concentrating power producing apparatus at a single point instead of distributing it throughout the premises of the various customers served is the tremendous aggregate saving in space. As the size of the 
units increases, the saving in space occupied becomes marked. For instance, a 10,000-kw. turbo-generator does not take up anything like ten times as much space as a $1000-\mathrm{kw}$. generator. In fact the space occupied is but little more than for a $1000-\mathrm{kw}$. unit, and when we compare the space occupied by a $10,000-\mathrm{kw}$. unit with a $100-\mathrm{kw}$. unit, the discrepancy is still more marked.

The aggregate saving in space occupied in housing of plant and in the auxiliary equipment will evidently amount to a large item and the comparison of central station power versus individual plants will result in a very material reduction in the first cost of the former compared to the latter.

\section{Economies Due to a Large Plant}

The reduction in first cost per kilowatt of a large plant over a small one is by no means the only economy from the concentration of a large amount of power generating apparatus at one point. In fact the reduction in first cost is only a small part of the total saving that can be obtained by such a move.

The total cost of power may be divided into two parts; viz. first annual fixed charges (interest, depreciation, taxes and insurance), that depend upon the first cost and second, operating costs (fuel, labor, repairs, supplies, and superintendence) that are almost entirely independent of the first cost. We have just seen that size has a considerable influence on the first of these divisions and now we propose to show this influence is still more marked on the second division. The proportion that fixed charges enter total power costs is usually somewhere between 30 per cent and 60 per cent, being smaller with small plants. The reason that fixed charges increase in proportion as the size of the plant decreases is not on account of the inherent decrease of this item (because, as we have already seen, it really increases) but because operating costs increase with decrease in size much faster than do fixed charges.

A preceding paragraph of this discussion has called attention to the fact that the larger the plant, the greater refinements it can afford to install. The first matter that requires attention as the size increases is usually the matter of fuel saving. In large plants the cost of fuel usually amounts to somewhere between 50 per cent and 75 per cent of the total operating expense. Obviously, therefore, the fuel bill offers by far the best target when one goes hunting for economy. In plants of small output the fuel bill bears a smaller proportion to the total, not 
at all because of better economy but because the other expenses, such as labor, superintendence, etc., go down slower than does fuel as the plant size decreases.

The condenser is undoubtedly the most important piece of apparatus so far as fuel economy is concerned. A large plant is almost invariably placed where suitable condensing water can be obtained, whereas a plant for serving the individual customer has to go on that customer's premises and even if the expense of a condenser is warranted, in a great many cases suitable condensing water is not a vailable except at a cost which makes its use prohibitive. The inherent fuel economy of condensing units as compared with non-condensing units is nearly in the ratio of two to one and it can, therefore, be seen at once how large a factor the condenser becomes in the matter of economical operation.

As the plant increases in size we soon come to a point where an investment in superheaters and economizers will begin to pay. The economy effected by these devices in a large plant is of the order of about 10 per cent of the fuel. When our fuel bill is of the order of 50 per cent of the total cost of power, it is evident such a saving will justify a very considerable expenditure. As the plant output grows smaller, however, the fuel bill becomes a constanty decreasing proportion of the total cost and at the same time the relative cost of superheater and economizers increases, so that we soon arrive at a point where their installation will no longer pay. It is only the plant of comparatively large output that can afford to use this economy.

Uniformity in fuel supply is another item which is of very considerable importance, as is realized by those who have been obliged to change the quality of fuel fired from time to time. The grates, draft, combustion chamber, etc. suitable for one kind of fuel may not be at all suitable for another, and the insurance of a uniform fuel supply is not within the power of the user of fuel in comparatively small quantities. It is only large plants which buy fuel at wholesale that can afford to have a guaranteed and uniform supply. The purchase of fuel under specifications is a refinement in fuel practice that has come into very considerable vogue within the past five or ten years. It is only such plants as use fuel in large quantities that can avail themselves of the uniformity of fuel supply which the purchase of fuel under such specifications will insure.

Some of our larger central stations have found that uniformity in the size of the particles of fuel has an important bearing on 
the economy with which it can be burned under boilers. In some plants it has been demonstrated that it is economy to screen the fuel so that dust and small particles may be separated from the larger and burned in a separate furnace particularly designed with that end in view. It is evident that only a plant having a comparatively large fuel consumption can afford to enter into such a refinement in the use of its fuel. Here is another economy that is available only in a larger plant.

After fuel, labor is the next largest of the items that go to make up operating cost. In the large plants it is possible to introduce labor saving devices, that would be out of the question in the small plant. Probably one of the greatest labor saving devices in the modern power plant is the mechanical stoker. Not only does the mechanical stoker save labor but it also gives an ability to force boilers to a point not possible with hand firing. Thus an indirect saving comes from the use of mechanical stokers (in reducing boiler equipment necessary during peaks) that is as great, if not greater, than their effect in the direct saving of labor. In the small plants the installation of mechanical stokers is not justified, because, even with hand firing the boiler room force is so small that it could not be further reduced by introducing stokers.

Again when we come to analyze engine room labor, it is evident that a $10,000-\mathrm{kw}$. turbo-generator does not require much more attention than a $100-\mathrm{kw}$. unit. Each unit has about the same number of bearings and there is little inherent reason for the large unit requiring much more attention than the small one. When we compare them on a per kilowatt basis, the large unit, of course, has a tremendous advantage in labor cost.

In a small plant we will find that the coal supply is brought in from the coal pile in a wheel-barrow and shovelled into the furnace by hand. In the large plant the incoming coal is dumped by gravity from a hopper car and carried almost automatically by machinery into bins above the furnaces where it is fed by gravity to the grates. The difference in labor is, of course, very marked, but it would be ridiculous for the small plant to attempt to use such coal handling machinery, because the amount of labor which it could save would not begin to pay for the fixed charges on the machinery.

The removal of ashes is another point wherein the large plant has an advantage on account of its size. The small plant must have them raked out by hand, loaded into a wheel-barrow and 
hauled away to a pile that is again moved by hand when a suffcient amount has accumulated. The large plant dumps them into a tram-car that takes them directly to a hopper car for disposal at once.

Another item of economy which can be exercised by the large plant, but is prohibited to the small one, is that of adjusting the apparatus to the load to be carried. A large plant usually is equipped with a comparatively large number of units and can operate them so that the units are run near their maximum economy point. On the other hand, a small plant is usually equipped with a relatively small number of units and must often run a unit considerably larger than necessary to take care of the load and consequently operate it at a relatively low point on its economy curve.

And so one may go on indefinitely and enumerate the advantages and economies of the large central station. If the boiler feed water is bad, the large plant can afford to install a water softening plant; the small plant cannot think of such a refinement. The large station can afford to insure itself against a coal miners' strike by installing a coal storage yard, and to insure itself against electrical breakdowns by spare units, spare cables and a double set of buses-refinements that would be entirely out of reach of the individual small plant.

It is evident, therefore, from the foregoing analysis that not only does the central station have an advantage in first cost but that it has a much greater advantage both in operating cost and in the ability to insure continuity of service.

\section{Diversity Factor}

Now we come to the third advantage of the large central station serving a diversified load. As the name indicates, diversity factor might be defined as the advantage in capacity which is secured by the large plant serving many different kinds of loads over the aggregate capacity of the many plants that would be required to serve each individual part of this load separately. Not only is the large station cheaper per kilowatt than the small one, but also the large plant does not have to have as many kilowatts of capacity installed to take care of a given aggregate load as would individual plants for taking care of the same service.

The diversity of two or more loads may be complete or only partial. Diversity may also occur on account of either yearly 
or daily fluctuations in the time that the maximum of a given load occurs. As an example of yearly fluctuations we might cite, as summer loads, ventilating fans, irrigation, pleasure parks and ice making; as winter loads, electric heating (as for street cars and houses) and electric lighting during the early hours of the daily lighting period. As examples of diversity factor due to daily variations we might cite power for the operation of factories during the day and the power required for illuminating the streets at night. These are examples where the diversity is nearly, if not quite complete, as there is no coincidence whatever of the times at which such loads must be carried.

Partial diversity is always secured between two loads unless the loads vary in exactly the same proportion at exactly the same time. Such a coincidence is impossible, and as a consequence any loads will have some diversity in the times at which their maxima will be taken.

One of the best examples of diversity that the writer knows of is the use of one of the United States Government irrigation plants in the west for house heating during the winter monthsa use which was called to my attention by Mr. O. H. Ensign, Chief Engineer of the United States Reclammation service. The power plant in this case was installed primarily for the purpose of pumping water for the irrigation of some of the arid lands of Idaho. The irrigation season in Idaho opens in April and closes usually in September, operating for this purpose only during the summer months. During the winter months there is ample water to run the plant and practically the only expense of its operation during the winter is the labor necessary for attendance. It is evident that the machinery will have less depreciation if operated during the winter months than if simply shut down and left uncared for. There is not the same chance for the apparatus to absorb moisture and it will unquestionably be in a better shape for this operation than if not operated during the winter.

In this Idaho irrigation district, advantage is taken of this condition by supplying electric heat to the farmers during the winter months at a price that will simply pay the cost of operation. This policy results in a price of the order of one-tenth cent per $\mathrm{kw}-\mathrm{hr}$. With such a price, one dollar will buy $3,420,000$ B.t.u. With coal running 10,000 B.t.u. per $1 \mathrm{~b}$. and selling at $\$ 4.00$ per ton (which is certainly a favorable statement of the fuel conditions in this district) one dollar will buy 5,000,000 B.t.u. An 
efficiency of 50 per cent is certainly all that can be expected in burning fuel for house heating purposes, while with electric heat one cannot avoid an efficiency of 100 per cent. As a consequence, we have the condition where the farmers of Idaho are able to heat their houses by electricity actually cheaper than by coal, to say nothing of the greater convenience and cleanliness of the electric method of heating-and this all comes on account of the existence of diversity factor.

Complete diversity occurs only with certain limited kinds of service; partial diversity occurs on every kind of service. The amount of partial diversity which occurs depends entirely upon the nature of that service. Mr. H. B. Gear, in an interesting paper read before the Chicago Section of this Institute in 1910, gives some valuable data on the question of diversity factor. He found, for instance, that in residence lighting the diversity factor amounted to over six, that is, the sum of the maxima of a considerable number of residences was over six times as great as the maximum required from the generating station to serve all of these residences. For commercial lighting, that is, the lighting of retail stores, etc. he found a diversity of nearly $2 \frac{1}{2}$; for small scattered service he found a diversity of practically the same figure and for large users the diversity was still 1.4. Possibly this last figure is the most significant of all. It is the large user who would be tempted to install a plant for his own operation. Residence lighting and small scattered power, etc. use such a small quantity of energy that there is practically no incentive for such users to provide their own power. However, the fact that the large user still has a diversity as high as $\mathbf{1 . 4}$ is, of itself, sufficient to enable a large central station to supply power to such users cheaper than they can make it themselves. This one consideration, independent of the others that are discussed in this paper, is sufficient to justify the central power station, because it means the installation of less than three-fourths the amount of apparatus in a central station than it would require in separate individual plants for giving the same service.

Even where various services are of the same kind there is a considerable amount of diversity. Mr. Samuel Insull, in an interesting and instructive paper read before this Institute in April, 1912, has shown this to be true. He finds, for instance, that the diversity for the operation of the various steam railroads centering in New York is of the order of some six or eight per cent. When it is borne in mind that this is the diversity for the same 
kinds of service, it is evident that the diversity between different kinds of service will be very much greater. It is important, therefore, that a central station diversifies its service just as far as possible. For instance, a plant whose main business is to supply lighting and general power can take on a railway load more economically than can a plant whose output is already being taken by railroads. On account of the diversity between these different types of load, the addition of a railway load may be assured by a plant already carrying a general power and lighting load with the addition of less apparatus than required by a separate plant to serve the same load. Concentration of power supply makes for economy in every aspect.

There are two arguments that may, with reason, be urged against the central station method of supply. The first is that the central station requires the addition of a transmitting and distributing system before its customers can be supplied and the cost, upkeep and losses in this transmitting and distributing system must be added to the central station to make it comparaable with individual customers' plants. This argument is entirely legitimate, as far as it goes, but it does not go far enough. The cost and losses of the transmitting and distributing system do not amount to enough to begin to offset the advantages on part of the central station that have been detailed in the preceding pages. It is, of course, possible to imagine a condition where the cost and losses of transmission and distribution make the central station supply more expensive than an isolated plant but this means that we have gone beyond the proper radius of that station. The advantages (in the matter of cost) of the central station are so great that the utmost addition, on account of transmission and distribution, and still maintain good regulation, are not sufficient to permit isolated plants to compete.

The second argument in favor of the isolated plant is that during the season that heating is required the steam may be used twice, once for power and the exhaust for heating. This is also a legitimate argument so far as it goes and its complete discussion requires much more space than I have at my disposal here. In general, however, it can be shown that the advantages which accrue to the centralization of a large amount of power at one point will far outweigh the advantage of the isolated plant even when it is coupled with the heating proposition, as it so often is.

When the isolated plant is used for heating, we must bear in 
mind that there is a large part of the year, certainly more than one-half of it, when no heating whatever is required and during this period the plant must accept the losses which are inherent with the combination of power generating and steam heating plant using the same steam. Another thing which must not be forgotten is the daily diversity between the heat and power loads in the isolated plant. Take for example, the case of an office building. The building will, of course, cool off to a certain extent during the night and it is required that it be brought to a certain acceptable temperature by the time the office force arrives in the morning. This will require a considerable amount of steam during the early morning hours at which period there is absolutely no use for light in the building and practically none for power. The heavy demand for light and power in this same office building will occur just before the force is getting ready to leave for the night and at this particular period of the day the requirements for heat are at a minimum because the heat inertia of the building is sufficient to keep up the temperature at this time, and it is useless to put in more heat at the time when the force is getting ready to leave. Therefore, while it is perfectly true that the same steam can be used economically for lighting and heating, it is impossible to so arrange a combination plant of this kind that the diversity in time requirements for the different kinds of service make it possible to make complete use of this advantage. This is a case where diversity works against and not for economy.

As a result of the foregoing analysis, the writer is of the opinion that there are only two reasons why central stations should not supply all of the electrical service within legitimate reach of their distributing systems. These are, first because the rate offered by the central station does not bear a suitable relation to the cost of the service to be supplied, and

Second, because the prospective customer has some motive other than the cost of the supply for not taking his service from the central station. 